\title{
Rupture of right coronary artery aneurysm into the right atrium
}

\author{
R. W. G. CHAPMAN AND J. WATKINS \\ From Wessex Cardiac and Thoracic Centre, Southampton Western Hospital, Oakley Road, Millbrook, \\ Southampton
}

SUMMARY A 63-year-old man presented with acute congestive heart failure and was found to have a continuous murmur. Two years earlier, he had an inferior myocardial infarct, when no murmurs were heard. Angiography showed a right coronary artery aneurysm communicating with the right atrium. The distal vessel was occluded. The aneurysm was resected and the patient remains well. It is proposed that this was a congenital aneurysm which led firstly to the myocardial infarct and finally ruptured into the right atrium.

Congenital fistulae between coronary artery aneurysms and all four chambers of the heart have been described but are rare (Masuya et al., 1975; de Nef et al., 1971; Mozen, 1956).

We report a case of acquired fistulous connection between a right coronary artery aneurysm and the right atrium. To our knowledge, no such case has previously been diagnosed in life, and has only twice been described post mortem, first by Harris in 1937 and secondly by Marano et al. in 1945; the latter case being associated with syphilitic aortitis.

\section{Case report}

A 63-year-old retired publisher was admitted to hospital in August 1975, with a 6 weeks' history of increasing breathlessness and palpitations. Two years previously he had had an inferior myocardial infarct, shown by electrocardiograms and confirmed by increased cardiac enzymes. No murmur was heard during the illness, or on follow-up examinations, and he made an apparently full recovery.

On examination he was dyspnoeic at rest and in severe congestive heart failure in sinus rhythm with a blood pressure of $160 / 80 \mathrm{mmHg}$. There was a grade $3 / 4$ continuous murmur, best heard at the lower left sternal edge, with tricuspid and mitral diastolic murmurs and a loud third heart sound. His chest $x$-ray showed a large heart with a cardiothoracic ratio of 56 per cent and plethoric lung fields. The electrocardiogram showed left ventri-

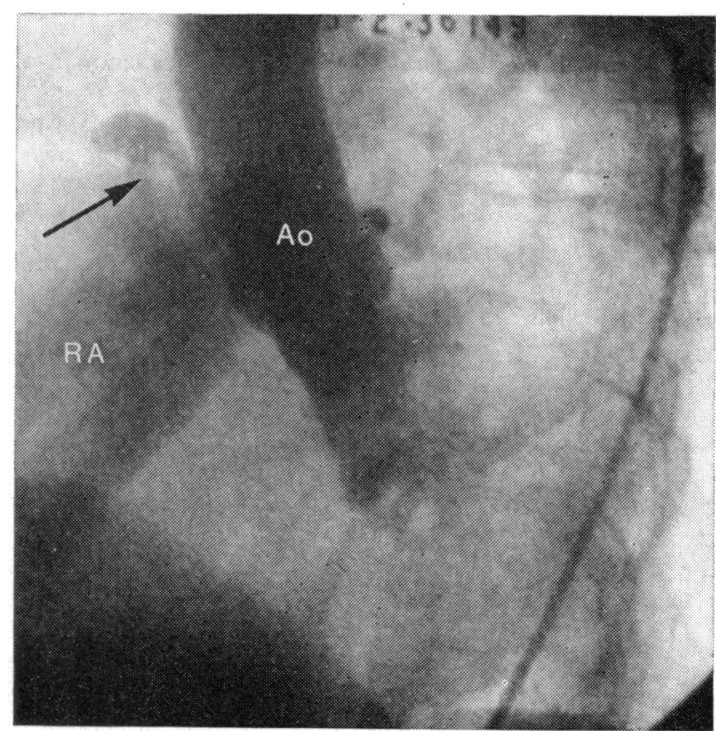

Fig. Right coronary artery aneurysm with fistulous connection to right atrium (arrowed).

cular hypertrophy and confirmed an old inferior myocardial infarct. Serological tests for syphilis were negative. Root aortography showed a large saccular aneurysm of the right coronary artery communicating with the right atrium (Fig.). Selective coronary arteriography showed total occlusion of the right coronary artery distal to the aneurysm. There 
was a left-to-right shunt at atrial level, giving a pulmonary/systemic flow rate of $1 \cdot 5 / 1$.

These findings were confirmed at operation ( $\mathrm{Mr}$ J. K. Ross) in August 1975. The coronary fistula was obliterated, and the aneurysm sac which contained laminated clot and measured $5 \times 3 \mathrm{~cm}$ was resected. His postoperative course was uneventful, and he remains well on no medication.

\section{Discussion}

We propose that this patient had a congenital right coronary artery aneurysm, which finally led to distal occlusion of the right coronary artery and inferior myocardial infarction.

The sudden development two years later of congestive heart failure and a loud continuous murmur strongly suggests that the aneurysm ruptured into the right atrium at that time.

Most patients with congenital coronary artery fistulae are asymptomatic and are referred at an early age because of the discovery of a loud continuous murmur on routine examination (de Nef et al., 1971). In our patient, however, no murmur was audible before his illness in 1975, strongly suggesting that there was no previous fistulous connection between the aneurysm and the right atrium.

In a review by Scott in 1948 of congenital coronary aneurysms, the commonest cause of death was rupture followed by coronary thrombosis, with occlusion of the artery at, or distal to, the aneurysm sac. Our patient was doubly fortunate in that he survived both events.

\section{Conclusion}

While there are no distinctive clinical signs of uncomplicated coronary artery aneurysm, the development of sudden congestive heart failure and a continuous murmur, with plethoric lung fields on chest $x$-ray film should indicate the possibility of this diagnosis.

\section{References}

de Nef, J. J. E., Vargherse, P. J., and Losekoot, G. (1971). Congenital coronary fistula-analysis of 17 cases. British Heart fournal, 33, 857-862.

Harris, P. N. (1937). Aneurysmal dilatation of the cardiac coronary arteries. Review of the literature and report of a case. American fournal of Pathology, 13, 89-98.

Marano, A., Baila, M., and Cardeza, A. (1945). Coronary aneurysm of the right coronary artery ruptured with the interauricular septum. Revista de la Asociación Médica Argentina, 59, 851-854.

Masuya, K., Kusonoki, N., Hara, S., Funatsu, T., Takegoshi, N., Murakami, E., Ueyama, T., and Takeda, R. (1975). Congenital right coronary artery fistula communicating with the left ventricle. Southern Medical fournal, 68, 1007-1010.

Mozen, H. E. (1956). Congenital cirsoid aneurysm of a coronary artery with associated artero-atrial fistula, treated by operation. Annals of Surgery, 144, 215-217.

Scott, D. H. (1948). Aneurysms of the coronary arteries. American Heart fournal, 36, 403-421.

Requests for reprints to Dr J. Watkins, Southampton Western Hospital, Oakley Road, Millbrook, Southampton. 